\title{
Model-Based Approach for Combustion Monitoring Using Real-Time Chemical Reactor Network
}

\author{
Pieter DePape and Igor Novosselov 1 \\ Department of Mechanical Engineering, University of Washington, Seattle, WA 98195, USA \\ Correspondence should be addressed to Igor Novosselov; ivn@uw.edu
}

Received 27 May 2018; Revised 1 August 2018; Accepted 5 September 2018; Published 1 October 2018

Academic Editor: Li Qiao

Copyright (C) 2018 Pieter DePape and Igor Novosselov. This is an open access article distributed under the Creative Commons Attribution License, which permits unrestricted use, distribution, and reproduction in any medium, provided the original work is properly cited.

\begin{abstract}
Flame stability and pollution control are significant problems in the design and operation of any combustion system. Realtime monitoring and analysis of these phenomena require sophisticated equipment and are often incompatible with practical applications. This work explores the feasibility of model-based combustion monitoring and real-time evaluation of proximity to lean blowout (LBO). The approach uses temperature measurements, coupled with Chemical Reactor Network (CRN) model to interpret the data in real-time. The objective is to provide a computationally fast means of interpreting measurements regarding proximity to LBO. The CRN-predicted free radical concentrations and their trends and ratios are studied in each combustion zone. Flame stability and a blowout of an atmospheric pressure laboratory combustor are investigated experimentally and via a phenomenological real-time Chemical Reactor Network (CRN). The reactor is operated on low heating value fuel stream, i.e., methane diluted with nitrogen with $\mathrm{N}_{2} / \mathrm{CH}_{4}$ volume ratios of 2.25 and 3.0. The data show a stable flame-zone carbon monoxide (CO) level over the entire range of the fuel-air equivalence ratio $(\Phi)$, and a significant increase in hydrocarbon emissions approaching blowout. The CRN trends agree with the data: the calculated concentrations of hydroxide $(\mathrm{OH}), \mathrm{O}$-atom, and $\mathrm{H}$-atom monotonically decrease with the reduction of $\Phi$. The flame $\mathrm{OH}$ blowout threshold is $0.025 \%$ by volume for both fuel mixtures. The real-time CRN allows for augmentation of combustion temperature measurements with modeled free radical concentrations and monitoring of unmeasurable combustion characteristics such as pollution formation rates, combustion efficiency, and proximity to blowout. This model-based approach for process monitoring can be useful in applications where the combustion measurements are limited to temperature and optical methods, or continuous gas sampling is not practical.
\end{abstract}

\section{Introduction}

Lean blowout can be defined as the phenomenon of flame extinction due to the reduction of the fuel-air ratio beyond a minimum threshold limit at which a given geometry can sustain a flame. The $\mathrm{NO}_{x}$ and soot emissions can be controlled by lowering the flame temperature through leaning of the flame fuel-air equivalence ratio $(\Phi)$. However, by operating very lean, the combustors have limited margins between stable combustion and lean flame instabilities leading to lean blowout. Lean-premixed concepts have been investigated by several aircraft engines developers $[1,2]$, where the flame instability and extinction is a primary safety concern. Owing to the expensive and potentially dangerous implications, predicting and preventing $\mathrm{LBO}$ is of considerable interest to researchers and practitioners. Blowout has mainly been studied in terms of the residence time of reactants [3-5] and flame structures and corresponding strain rates $[6,7]$. The Damkohler number $(\mathrm{Da})$ is used for $\mathrm{LBO}$ characterization; it is defined as the ratio of mixing time to the chemical time $\left(\tau_{\text {mix }} / \tau_{\text {chem }}\right)$. For aerodynamically stabilized reactors, blowout occurs when the rate of entrainment of reactants into the recirculation zone cannot be balanced by the rate of their consumption [8]. Da nonuniformity can also lead to the onset of flow instabilities resulting in LBO [9]. Experimental and numerical studies have investigated species distribution in different combustor geometries, injector designs and fuel compositions e.g., [10-17]. Lean flame blowout modeling for an aeroengine application using zonal modeling was reported in [18-20]. Several authors have related the $\mathrm{OH}$ radical in the flame and post-flame zone to a blowout [9, 21-23]. The CFD models used to predict the species field are computationally 
intensive and cannot be used for real-time calculations. Recently, fast phenomenological CRN and semiempirical approaches $[24,25]$ for aeroengine LBO prediction have been proposed. Real-time species calculations methodology has been implemented for high-intensity atmospheric jet stirred reactor approaching blow out; the authors used $\mathrm{OH}$ trends in three-zone CRN to predict reactor proximity to blowout [26].

The chemical reactor modeling approach has been shown to be useful for the development of global and reduced kinetic mechanisms and their validation against full-length mechanisms [27-29]. Early gas turbine combustors were modeled by [30] in the 1950s as an arrangement of a perfectly stirred reactor (PSR) for the high-intensity primary zone of the combustor, followed by a plug flow reactor (PFR) for the burnout zone of the combustor. Zonal combustion modeling [31] is an improvement for combustor design via correlation parameters. In zonal modeling, the combustor volume is divided into idealized PSR and PFR elements, where the flow conditions for the elements can be calculated based on the dissipation gradient method. Simple chemical reactor models have been used for evaluating pollutant emission trends in laboratory combustors, e.g., [32-36]. While these approaches provide quick and useful insight into emission trends, more advanced CRNs containing ten or more reactor elements can address the complex flow field inside the combustor. Typically, the developments of such CRNs are guided by the CFD simulations of the flow field and reaction space of the combustor. The CFD-CRN translation is based on several flow field parameters: species concentrations, reaction rates, turbulence parameters, and temperature. The following information is used for developing the CRN framework: the number of elements and element types, sizes, and linkages. Such CRNs have been used for practical swirl stabilized combustors, e.g., [28, 29, 37, 38]. Large CRN models have been used for hydrocarbons, $\mathrm{NO}_{x}$, and $\mathrm{CO}$ predictions in practical combustors, e.g., [38-43]. The commercialization of the Chemkin code of [44] led to the development of an automated tool for the generation of Equivalent Reactor Networks (ERN) [45]. The ERN is often an extension of the CFD post-processing. Though recently there have been an increased number of publications demonstrating the ERN for combustion systems, this topic is beyond the scope of this work as the ERN approach is used in conjunction with CFD and does not allow for the real-time modeling of the combustion process.

Of particular interest to this work is the CRN modeling of low heating value fuels associated with solid fuels combustion, e.g., the early reports [46] investigated the use of the modeling for optimization for reducing NOx emissions from pulverized coal-fired furnaces. Several researchers represented pulverized fuel furnaces as ideal reactor models to incorporate detailed NOx formation chemistry. For example, [47-49] used chemical reactor networks for representing combustion in industrial furnaces for predicting NOx using a detailed kinetic mechanism. A unique, phenomenological approach was used by Niska et al. [50]. Instead of dividing the furnace into different volumes based on the physical location, they divided the flow field based on the characteristic chemical process prevailing in each region, such as the primary flame zone, the recirculation zone, the over-fire air zone, the mixing layer, and the burnout zone. The approach was implemented to study the formation of NOx in biomass combustion [51, 52] Some more recent publications related to low heating value fuels use chemical kinetics modeling to study biomass pyrolysis, e.g., [53], and combustion of solid fuels, e.g., [54].

Related to this work, the in-house CRN code was originally developed by Pratt and co-workers who also applied the software to model high-intensity combustors, e.g., [5558]. The PSR reactor concept is implemented by balancing the Arrhenius source terms of net production of each species by convective removal of that species from the PSR control volume. The PFR is modeled by a series of PSRs. The code has been modified by other researchers [28, 41, 59]. One of the major benefits of this code is in the implementation of the fast convergence algorithm, e.g., [60], which enables fast chemical kinetic calculations in networks.

The majority of the literature related to the development and use of CRNs aims to predict the emissions of combustion systems accurately. These CRNs or ERNs are developed based on CFD solutions and are used as reduced order simulations with the number of the elements orders of magnitude lower than in the CFD. The grid reduction allows for the use of a detailed chemical kinetic mechanism to gain insight into the pollution formation and blowout conditions and often provides feedback to the CFD models [45]. Our approach does not rely on the analysis (post-processing) of the complex flow field from CFD, but, rather, it aims at creating the simplest (fastest) reactor arrangement that can estimate combustor behavior trends in real-time.

Our primary aims are (i) to develop a simple (fast) phenomenological CRN model for an experimental combustor operated on low heating value fuel for a range of fuel-air equivalence ratios and fuel heating values, (ii) to validate CRN trends for major combustion species concentrations against experimental data and obtain free radical concentrations (not measured in the experiment), and (iii) to evaluate the CRN ability to estimate system proximity to lean flame blowout by analyzing the modeled free radical concentrations in the combustor in real-time. The approach is useful for monitoring and analyzing combustor performance by providing user extended information about combustion parameters that are difficult to measure in a practical system (e.g., free radical concentrations, temperature, and species gradients within the combustor, combustion efficiency, the pollution formation mechanism, and proximity to blowout thresholds). The current industrial combustion control methods largely rely on temperature and major combustion species measurements. The CRN can provide "data" without delay associated with measurements using gas analyzers. Combustion species measurements are difficult to make in mobile systems and are prohibitive in low-cost systems.

In this paper, we present a simple phenomenological CRN that can be used to describe combustion trends and nonmeasurable combustion characteristics over a range of fuel-air equivalence ratios and fuel compositions, providing real-time monitoring and analysis of the combustion process. This manuscript is structured in the following way: (a) a 


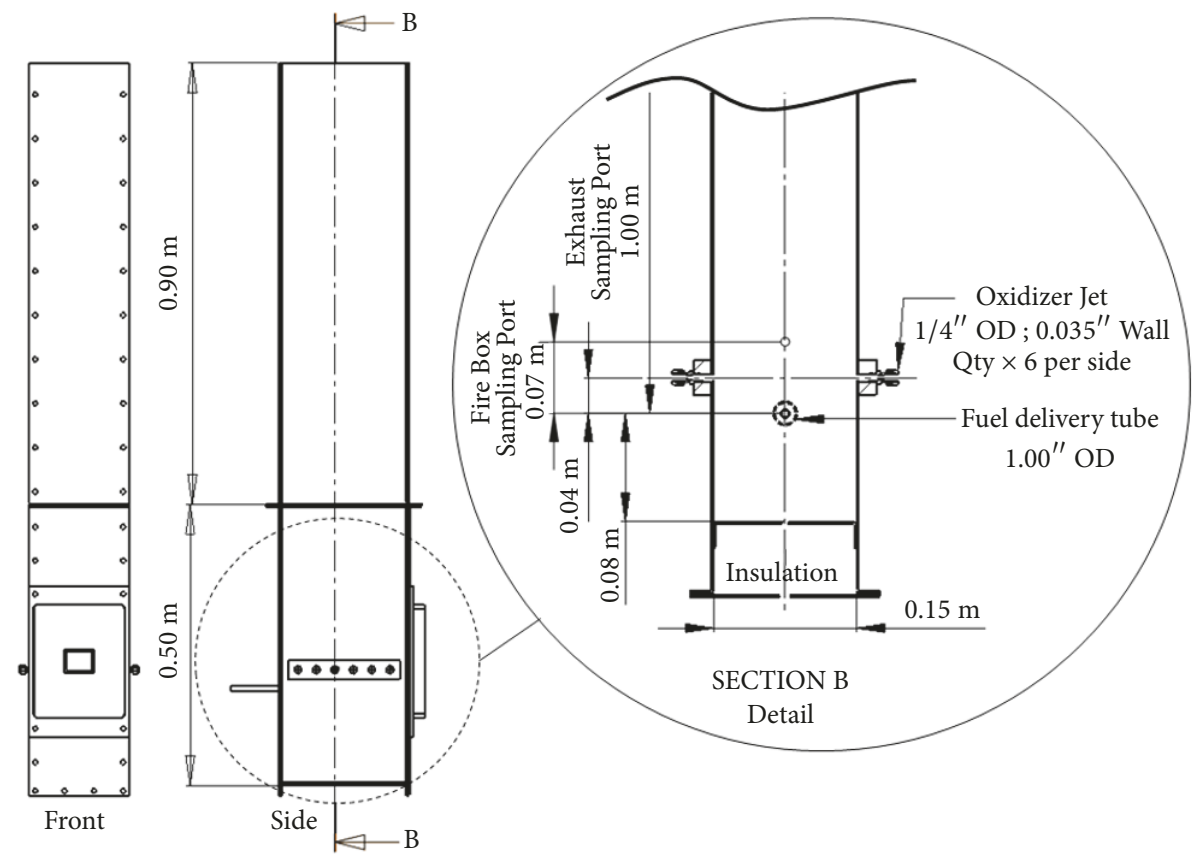

Figure 1: Drawing of the XTZ combustor. Air and fuel are delivered, respectively, through two banks of air jets and a centrally mounted fuel delivery tube. Two downstream gas sampling ports collect gas species and temperature data throughout the lean combustion regime until LBO occurs.

description of the novel experimental combustor for reduced heating value gases with heating values similar to the gases released from the devolatilization of a solid fuel, (b) a discussion of the experimental data obtained by the gas sampling of the flame and burn out/exhaust zones, and (c) a description and validation of the phenomenological 3-element CRN model (developed based on the experimental observations and measurements) without the use of CFD modeling. The CRN model is validated against the experimental results over the range of operating conditions. (d) Finally, we use the 3-element CRN to gain insight into the prediction of a lean flame blowout for two fuel mixtures by analyzing the computed free radical concentrations and trends in the flame PSR element.

\section{Experimental}

2.1. Reactor Design. The combustor that has been designed and built for this study provides an experimental system for the application and evaluation of a simple, phenomenological CRN model for the prediction of combustor performance, especially flame stability, combustor efficiency, and exhaust emissions. Additionally, the combustor can be used to study the combustion of reduced heating value fuels, such as the gases and volatile hydrocarbons released from a wood core undergoing thermal pyrolysis. Elsewhere, we discuss the use of a simple, phenomenological CRN to predict the exhaust emissions from a wood fired-combustor [61].

An atmospheric pressure combustor of a rectangular cross-section and 56-liter volume is built. The combustor design is shown in Figure 1. We divide the combustor into three characteristic zones in series based on the observation of the flame, the temperature, and combustion species measurements: (i) flame front/ignition, (ii) immediate post-flame, and (iii) plug flow burnout/exhaust. Thus, the experimental combustor is termed an experimental three-zone (XTZ) combustor. The model of the combustor is termed a three-element CRN, which is described later in the manuscript (see Figure 2). More complex models can be constructed; however, here we aim to describe the combustion process with a minimum number of reactors to enable real-time calculations.

For the present work, the fuel is methane diluted with nitrogen, giving a fuel lower heating value of 14,000$17,000 \mathrm{~kJ} / \mathrm{kg}$. This fuel is injected into the combustor through a porous tube, which runs horizontally from the back to the front of the lower part of the combustor. The fuel flow is out of and around the tube, culminating in an upward flow of fuel in the combustor. Two ratios of nitrogen to methane by volume, termed the dilution ratio, are used: 2.25 and 3.0. Above the fuel tube, jets of air injected from the side walls of the combustor mix with the upward moving fuel. Once the combustor is started with an electrical spark, the ignition is self-sustaining. The air jets are designed to provide a wellaerated flame front of blue luminosity; the combustion gases flow upward and undergo burnout and exhausting. A small fraction of the fuel-air bypasses the flame zones. This fuel flows upward along the side walls of the combustor and mixes with the combustion gases in the stack and burns. Although the flow field of the combustor is relatively complex, the linear arrangement of the three reaction zones provides the basis for developing a simple phenomenological CRN model. The three reaction zone description is based on both the 


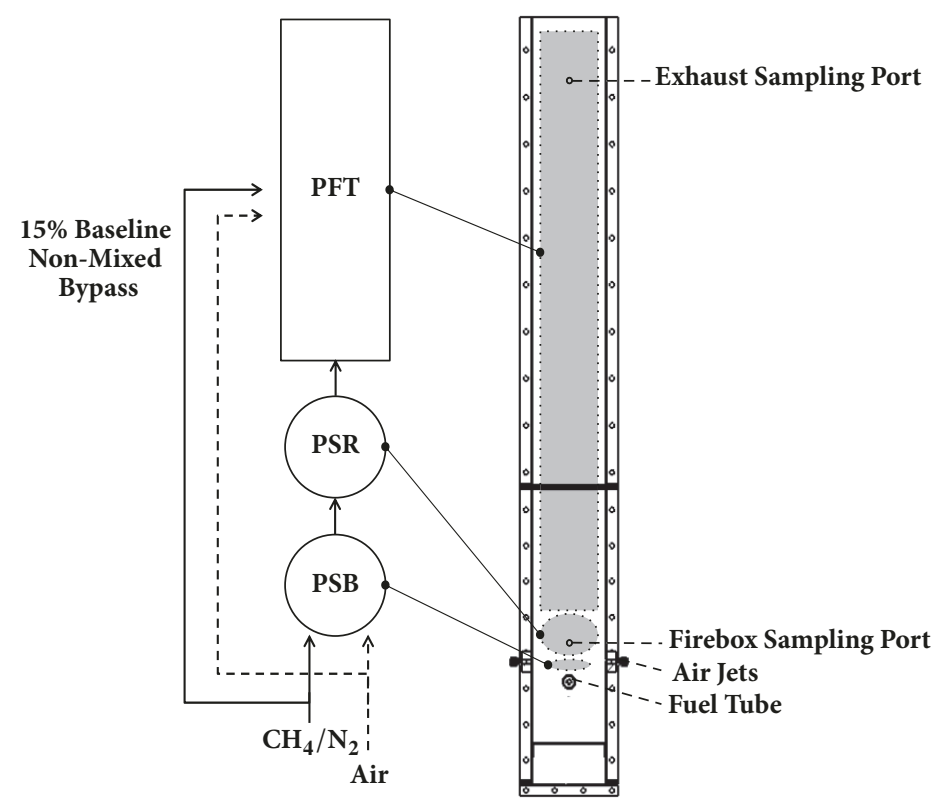

FIGURE 2: Three-element CRN model configured with unmixed fuel and air bypass of 15\% (baseline case). The fuel and air are introduced into the flame zone, which is modeled by a PSB followed by a PSR. The post-flame zone is modeled by a PFT.

visual observations of the flame and the probe measurements of the temperature and species concentrations within the combustor.

2.2. Experimental Setup and Procedure. The XTZ combustor is designed and built to provide experimental observations and data over a range of operating conditions. A drawing of the XTZ is shown in Figure 1.

The XTZ combustor has a modular design. Its overall dimensions are $0.150 \mathrm{~m}$ width and $0.27 \mathrm{~m}$ depth, giving a cross-sectional area of $0.040 \mathrm{~m}^{2}$ and a length (i.e., height) of $1.40 \mathrm{~m}$. The modules consist of an Inconel firebox, containing the flame zones, measuring $0.50 \mathrm{~m}$ in height, followed by a stainless-steel burnout section and exhaust stack, measuring $0.90 \mathrm{~m}$ in height. The entire rig is enclosed in ceramic wool insulation to mitigate heat loss and improve the accuracy of the adiabatic modeling in the firebox. An OD $0.025 \mathrm{~m}$ porous gas tube is used to deliver the gaseous fuel mixture of methane and nitrogen into the firebox. The fuel tube is located $0.08 \mathrm{~m}$ from the floor of the firebox. Low porosity of the fuel tube wall maintains the high pressure inside the tube. At all flow conditions, a uniform flame shape was observed indicating that fuel was evenly distributed along the fuel tube. Air enters the firebox through two banks of jets, one on each side wall of the firebox; the banks are located $0.04 \mathrm{~m}$ above the center axis of the fuel tube and consist of six equally spaced circular jets, each of $4.8 \mathrm{~mm}$ diameter. Mass flow controllers meter the air and fuel mass flow rates. The fuel is methane diluted with nitrogen, which, as stated above, allows for the combustion of reduced heating value fuels to be studied. The nitrogen addition increases the fuel inlet velocity pushing the flame front away from the fuel tube, thereby preventing the flame from attaching to the fuel tube. This helps to maintain the structural integrity of the fuel tube by curtailing the hightemperature oxidation of the metal tube.

Experiments are conducted at fuel-lean conditions, over a range of equivalence ratios from about $0.65 \Phi$ until LBO occurs. The total air flow rate of the combustor is held constant at $400 \mathrm{slpm}$, and the fuel flow rate is decreased incrementally. The nitrogen-to-methane dilution ratio is held constant at either 2.25 or 3.0. By maintaining a constant air flow rate, variations in the combustor's fluid dynamic behavior are mitigated. The nominal upward velocity of the hot gas in the combustor is $1 \mathrm{~m} / \mathrm{s}$, although as the temperature varies inside the combustor, the average velocity changes accordingly. Each operating condition is maintained until certain sampling parameters reach steady state. These parameters are the rig wall temperatures and gas sampling concentrations. These parameters, as well as the gas temperatures and air and fuel flow rates, are recorded at steady state.

Type-K thermocouples are used to measure the temperatures in the combustor. Thermocouples are located at several positions on the combustor walls. For gas temperature measurements, the type-K thermocouple wires are supported in a two-hole ceramic rod of OD $3 \mathrm{~mm}$. The welded thermocouple bead, uncoated, is located close to the end of the probe. Ports for inserting the gas temperature thermocouples and gas sampling probes are located in both the firebox and the exhaust stack. The firebox sampling port is located $0.07 \mathrm{~m}$ above the fuel tube axis (in the flame zone), and the exhaust stack sampling port is located $1 \mathrm{~m}$ above the fuel tube axis (in the combustor exhaust). An uncooled sampling probe is used for the exhaust. A water-cooled sampling probe is used to mitigate the oxidation of the gas sampled from the firebox. Both probes are constructed of stainless steel. In addition to the center of the cross-section measurements, area measurements are available for the firebox. The area 


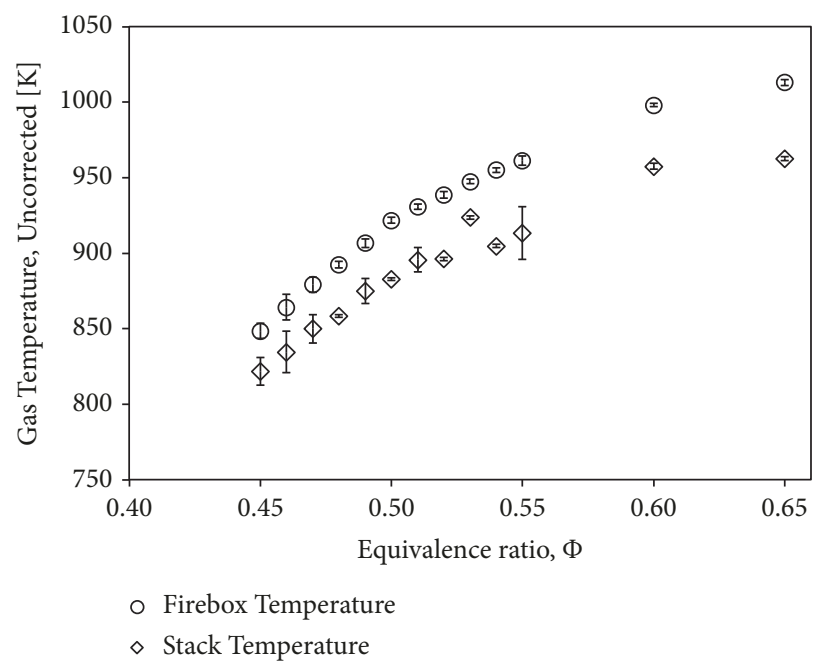

Figure 3: Measured, uncorrected temperatures for the firebox and exhaust for the baseline case with 2.25:1 nitrogen-to-methane dilution ratio, $\Phi$ range: 0.65 - 0.45 (LBO). Error bars are the standard deviation of six experimental runs. The thermocouple is located on the centerline of the combustor.

measurements are obtained by placing the thermocouple or the gas sampling probe, at various distances across the combustor and then pivoting the probe through an included angle of about 30 degrees in the plane of the cross-section. This procedure allows for about $40 \%$ of the cross-sectional area to be examined. These area measurements show $\pm 10 \%$ deviation from the average value. Only the centerline measurements are reported in this paper.

A Horiba 510 CO gas analyzer is used for the firebox gas measurements, and the exhaust gas sample is analyzed by a Horiba 534 four-gas analyzer. This is an unheated analyzer that measures the sum of the light hydrocarbon gases sampled. The Horiba 534 analyzer is calibrated on $\mathrm{CH}_{4}$. The samples are dried prior to analysis. All data are collected by UEIDAQ and OMEGA data acquisition units and virtually interfaced to the user through the National Instruments LabVIEW software. The National Instruments LabVIEW interface is also used for the control of the air and fuel mass flow rates through the same UEIDAQ unit.

2.3. Model Development. The CRN consists of a series of idealized chemical reactors that are networked together in a linear fashion to represent the XTZ combustor: (1) a PSB (perfectly stirred reactor at incipient blowout volume), which is a PSR limited to the smallest physical volume that will maintain a chemical reaction for that operating condition, (2) a PSR (perfectly stirred reactor) of assigned constant volume in which mixing to the molecular scale is assumed to happen instantaneously compared to the chemical reaction time, and (3) a PFR (plug flow reactor), in which the flow is assumed to move as a plug, and the chemical reaction proceeds one-dimensionally. Longitudinal mixing in the PFR is assumed to be zero. Specifically, a PSB is useful for igniting the mixture, a PSR is useful for simulating a flame zone of moderate to high intensity, and a PFR is useful for simulating the post-flame regions. Figure 2 shows the CRN used in this work. In this CRN, the PSB and PSR are assumed to be adiabatic reactors, and the plug flow reactor is assigned a nonadiabatic, single temperature or temperature gradient for each combustor case treated. Because of the assigned temperature measured at the firebox, this reactor is termed a PFT. The main goal of the CRN is to obtain reactor species concentrations for a range of fuel heating values and $\Phi$ with a minimum number of elements to achieve real-time calculations of combustion trends. This low computational cost CRN is developed without the use of CFD simulations, but rather based on the visual observations and experimental measurements of the temperature and major combustion species.

The well-aerated flame of the combustor is assumed to run at the overall fuel-air equivalence ratio of the combustor. This equivalence ratio is assumed for the PSB and PSR zones and is assumed to carry over to the PFT zone. Some of the fuel and air bypass the flame zones, i.e., the PSB and PSR zones, and mix into the PFT zone, where they may burn. The measurements shown in Figure 3 and Figure 4 suggest that none of the bypass fuel is oxidized at incipient LBO since no additional CO is formed at this condition. For the baseline case, the measured exhaust UHC at incipient LBO corresponds to a $15 \%$ bypass of the fuel. To satisfy conservation of mass, a $15 \%$ bypass of the air is assumed in the CRN model.

We use the UW-chemical reactor code [41] and the GRI 3.0 chemical kinetic mechanism for the CRN model. The UW code calculates the volume for an incipient blowout for each equivalence ratio treated. This is the PSB volume; it is $1 \%$ larger than the true blowout volume at any specific condition. As the equivalence ratio decreases, the PSB volume increases. At LBO, even if the volume is very large, a converged solution is not obtained. For the PSR volume, which represents the continuation of the flame, a fixed value of $82 \mathrm{~cm}^{3}$ is approximated based on visual observation of ellipsoid volume of the 


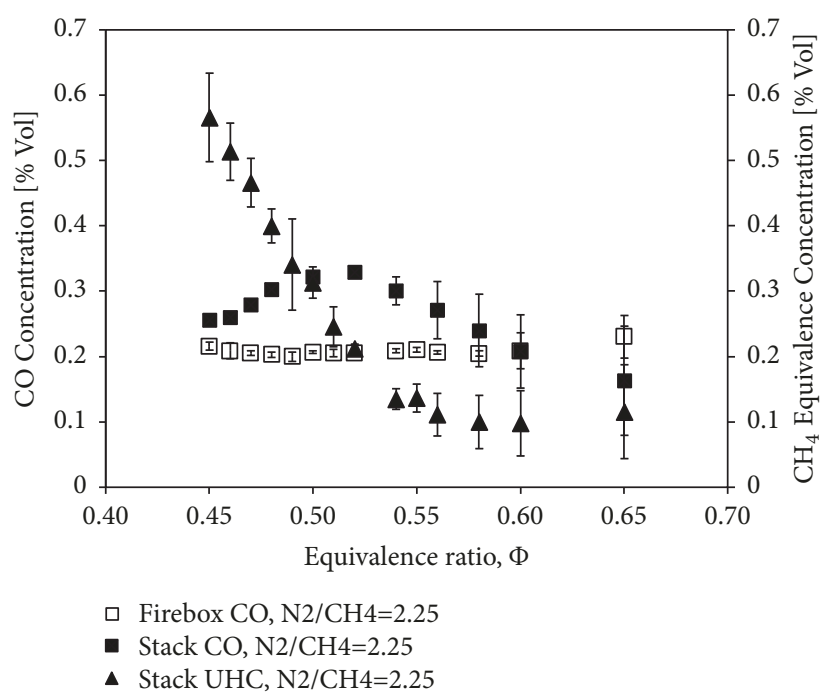

FIGURE 4: The measured firebox CO concentration and stack UHC and CO concentrations for an equivalence ratio of $0.65 \Phi$ to LBO at $0.45 \Phi$ for baseline conditions. The error bars are the standard deviation of six experimental runs. The sample probe is located in the cross-sectional center of the firebox and exhaust stack.

high luminosity region for baseline combustion case for the range of $\Phi=0.65$ to LBO. The PFT volume, a fixed value of 30 liters is used. The assigned operating temperature of the PFT is based on the experimental results and entered as a boundary condition into the code in real-time. Although the temperature in the experimental combustion is not uniform in this zone because of heat loss; a single value of the temperature is used in the code to construct the simplest CRN that can describe the exhaust emission trends and an incipient blowout over a range of operating conditions. The PFT temperature assumed in this work is the measured, uncorrected firebox temperature.

A comparison of computed and experimental results is shown in the next two sections of this paper. The CRN results for the PSR are compared to the firebox measurements, and the CRN results for the outlet of the PFT are compared to the exhaust stack measurements.

2.4. Experimental Results and Discussion. The baseline operating condition of the combustor is an air flow rate of 400 slpm and a nitrogen-to-methane dilution ratio of 2.25. LBO occurs at $0.45 \Phi$. The baseline condition is used for the development of the CRN. Figure 3 shows the gas temperature measurements against the equivalence ratio, from incipient LBO to $0.65 \Phi$. The temperature data are the raw data on the centerline, without correction for thermocouple heat loss by radiation and conduction. For the firebox, the average temperature varies from $850 \mathrm{~K}$ at incipient $\mathrm{LBO}$ to $1015 \mathrm{~K}$ at $0.65 \Phi$. The corresponding adiabatic flame temperatures (AFTs) are $1290 \mathrm{~K}$ and $1595 \mathrm{~K}$. The ATFs are calculated using the chemical kinetic code; the PSR element inputs (e.g., fuel composition, reactor dimensions, and flow rates) correspond to the experimental conditions. The exhaust measured temperature varies from $820 \mathrm{~K}$ at incipient $\mathrm{LBO}$ to $935 \mathrm{~K}$ at $0.65 \Phi$. The gas temperature decreases with decreasing $\Phi$ and drops more rapidly in both the firebox and the stack near LBO. The temperature measurements are lower than the adiabatic flame temperature. The reason for lower measured temperature is a combination of the following: (i) incomplete combustion, (ii) nonadiabaticity of the combustor, and (iii) heat loss from the thermocouple.

Figure 4 shows the measured $\mathrm{CO}$ and the methane equivalent UHC concentrations for the baseline case. The concentrations are measured dry. The $\mathrm{CO}$ concentration in the firebox is nearly constant at $0.25 \%$ by volume over the $\Phi$ range tested. As the equivalence ratio increases, more $\mathrm{CO}$ forms from the fuel, but the increasing temperature causes enhanced oxidation of the $\mathrm{CO}$ to $\mathrm{CO}_{2}$, resulting in a nearly constant $\mathrm{CO}$ concentration. The stack $\mathrm{CO}$ reaches a peak value of $0.33 \%$ by volume at about $0.50 \Phi$; the $\mathrm{CO}$ is lower at both richer and leaner equivalence ratios.

Figure 4 shows a significant increase in UHC at the stack near LBO. This increase in the UHC emissions agrees with the previous data from [39]. At incipient blowout, UHC is about $0.55 \%$ by volume; whereas, for equivalence ratios above $0.55 \Phi$, UHC is nearly constant at about $0.1 \%$ by volume. The UHC in the stack is the result of fuel bypassing the flame zones. In the stack, this fuel mixes with post-flame gases flowing upward from the flame and oxidizes. Near LBO, however, this oxidation process is weak due to the lower temperatures in the stack, leading to the poor conversion of UHC to CO. This trend is apparent in the CO fall and the increase of UHC values approaching blowout condition (below $0.50 \Phi)$. On the other hand, at the highest values of equivalence ratio, both the UHC and $\mathrm{CO}$ are fairly well oxidized to $\mathrm{CO}_{2}$.

Figure 5 shows the experimental data from the other nitrogen-to-methane dilution ratio: 3.0. The air flow rate remains at $400 \mathrm{slpm}$. Due to the increase in nitrogen, this case blows out at a higher equivalence ratio of $0.48 \Phi$, compared to $0.45 \Phi$ for the baseline case. The firebox $\mathrm{CO}$ concentration is similar to the baseline case and nearly constant at levels 


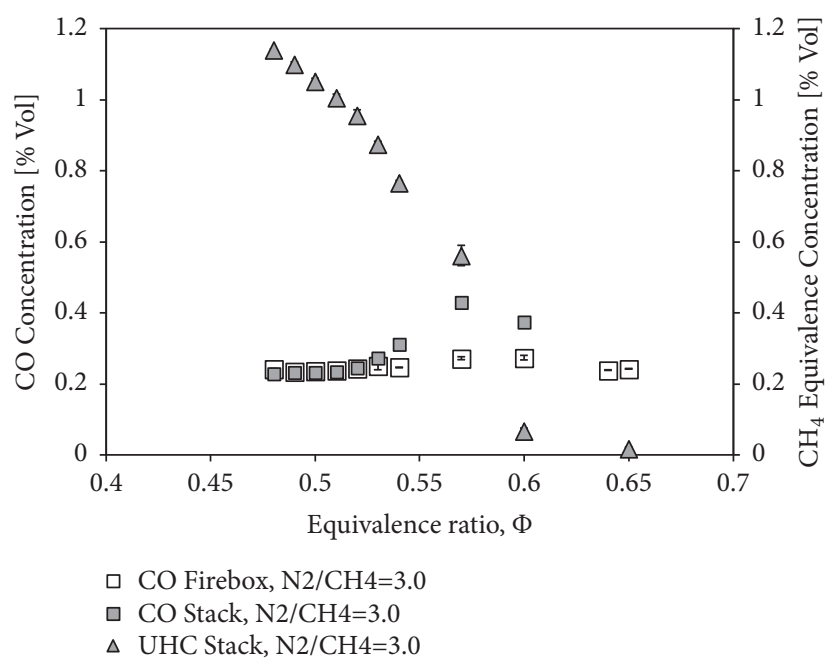

FIGURE 5: The measured firebox CO concentration and exhaust UHC and CO concentrations for the equivalence ratio range of $0.65 \Phi$ to LBO at $0.48 \Phi$. The operating conditions are the nitrogen-to-methane ratio of 3.0 and an air flow rate of $400 \mathrm{slpm}$. The error bars are the standard deviation between the experimental runs. Sample probes are located on the centerline.

of $\sim 0.25 \%$ by volume. The 3.0 dilution ratio case exhibits a similar stack CO trend to the baseline case. However, the values are somewhat different from the baseline case. The peak CO increases to about $0.4 \%$ by volume and occurs at a higher value of equivalence ratio of $0.57 \Phi$. The stack CO values are equal to the firebox CO value near the LBO.

The stack UHC data in Figure 5 shows a steeper dependence on equivalence ratio than for the baseline case $(2.25$ dilution). At incipient blowout, the UHC of $1.2 \%$ by volume is about double the UHC for the baseline case. The increased nitrogen causes an increase in unburned hydrocarbon in the stack at LBO. However, for the highest equivalence ratio tested $(0.65 \Phi)$, the UHC is well below $0.1 \%$ and, thus, lower than the baseline case. This behavior may be the result of enhanced mixing in the stack because of the presence of nitrogen and the increased flame volume due to the lower flame speed of the diluted methane flame.

In these experiments, the highest carbon conversion efficiencies occur at the highest value of equivalence ratio tested: $0.65 \Phi$. The carbon conversion efficiency is expressed as:

$$
\eta_{c}=1-\frac{(\mathrm{CO}+\mathrm{UHC})}{\mathrm{CO}_{2-\mathrm{cc}}}
$$

In this equation, the chemical species represent their mole percentages, dry basis. For both cases of fuel dilution, the carbon conversion efficiency for $0.65 \Phi$ is about $96 \%$.

\section{Model}

3.1. CRN Baseline Results. Figure 6 shows the comparison between the measurements and the CRN predictions for the baseline dilution case. The calculations are performed in near real-time (0.1-2 seconds delay). The fuel and air mass flow rate inputs into the CRN code are provided directly from the LabVIEW interface that controls the MFCs.
Only the steady the data at steady-state conditions (defined by temperature measurements in the flame and post-flame zones) are analyzed in this work, the transient data during the reactor warm up, cool down, or transition from one state to another are not considered. Depending on the combustor $\Phi$ the computation time increases as the reactor approaches blowout due to the stiffness of the problem. Trends between the CRN predictions and measurements are seen for the following:

(1) The LBO equivalence ratio is $0.45 \Phi$. The computed PSB volume at this condition is $500 \mathrm{~cm}^{3}$, which is consistent with the observations of the luminous, turbulent flame of this relatively large combustor. However, with the decreasing equivalence ratio (below $0.45 \Phi)$, the computed volume of this zone becomes unrealistically large.

(2) The nearly constant CO concentration of $0.25 \%$ in the firebox over the range of equivalence ratios used $(0.45 \Phi$ to $0.65 \Phi)$. This agreement is obtained using the fixed volume of the PSR of $82 \mathrm{~cm}^{3}$. Note that the constancy of $\mathrm{CO}$ in the flame over a large range of operating conditions suggests that the flame zone $\mathrm{CO}$ is not a good surrogate for predicting the combustor's proximity to LBO.

(3) The exhaust trends of UHC and CO with equivalence ratio. (3A) Trend agreement is seen in exhaust UHC, which decreases continuously from maximum UHC at incipient LBO (of about $0.55 \%$ ) to a small value (less than about $0.1 \%$ ) as the highest equivalence ratio of $0.65 \Phi$ is reached. (3B) Trend agreement is also seen in the exhaust CO. Starting at incipient LBO, the CO increases, reaching a peak value at an equivalence ratio of about $0.50 \Phi$. For higher values of equivalence ratio, the $\mathrm{CO}$ decreases. The $\mathrm{CRN}$ describes the oxidation trends of $\mathrm{UHC}$ to $\mathrm{CO}$, causing the $\mathrm{CO}$ to increase 


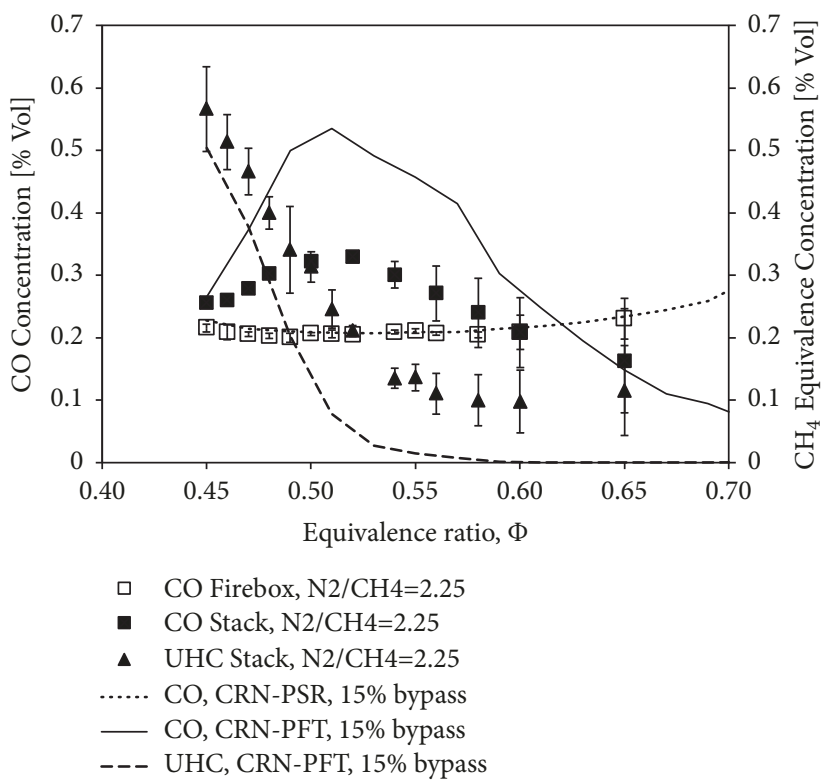

FIGURE 6: Comparison of CRN predictions of CO and UHC with the experimental measurements for the baseline dilution case: the PSR predictions are compared to the firebox measurements, and the PFT predictions are compared to the stack measurements.

with equivalence ratio at the leanest ratios, and it predicts the oxidation of $\mathrm{CO}$ to $\mathrm{CO}_{2}$, causing the $\mathrm{CO}$ to decrease at equivalence ratios richer than about $0.50 \Phi$. (3C) The numerical difference between the peak exhaust $\mathrm{CO}$ concentrations is $0.50 \%$ predicted and $0.33 \%$ measured. Although not done here, this difference can be reduced by adjusting the mixing rate of the bypass fuel into the plug flow zone. The lower UHC predictions are likely caused by the poor mixing of the bypass mixture and with hot products of combustion and possible combustion quenching at near the combustor wall in the experiments.

\subsection{CRN Analysis of Flame Zone Free Radical Concentrations.} In order to understand the proximity to $\mathrm{LBO}$, the threeelement $\mathrm{CRN}$ is used to examine free radical concentrations in the flame zone. The free radicals of interest are $\mathrm{OH}, \mathrm{O}$, and $\mathrm{H}$. Of these, the focus is on $\mathrm{OH}$, since it can be optically observed by well-established methods. The $\mathrm{OH}$ radical has been shown to be the longest surviving free radical in flames thus most likely available for continuous ignition of fresh fuel and air. Figure 7 shows the $\mathrm{OH}, \mathrm{O}$, and $\mathrm{H}$ concentrations in the PSR zone as a function of the equivalence ratio for the two nitrogen dilution ratios. The free radical concentrations decrease with decreasing equivalence ratio. At $\mathrm{LBO}$, the $\mathrm{OH}$ concentration is a threshold value of $0.025 \%$ by volume for each nitrogen dilution case; the combustion cannot be sustained in the present model if the calculated $\mathrm{OH}$ values below that level. The use of a CRN operating in real-time for determining the proximity of a combustor to $\mathrm{LBO}$ via the prediction of $\mathrm{OH}$ would offer an alternative to measurements of $\mathrm{OH} *$ [62] which largely depends on the behavior of the $\mathrm{CH}$ radical because of the reaction $\mathrm{CH}+\mathrm{O}_{2} \longrightarrow \mathrm{CO}+\mathrm{OH} *$, as shown in $[63,64]$.

\section{Conclusions}

In this manuscript, we demonstrate a novel approach for monitoring combustor performance by computing difficultto-measure combustion parameters using a real-time model. The low computational cost CRN models the free radical concentration and the rates of their formation and destruction in the main combustion zones, as well as the time-dependent trends and ratios within the combustor for predicting system response to the changes in operating conditions. Several conclusions and potential uses of this methodology are summarized below.

CRN Development. The phenomenological CRN is developed using the observations and data from the laboratory combustor without the use of CFD modeling. The CRN is used over a range of operating conditions. Inputs include fuel and air mass flow rates and fuel composition. The fuel is methane diluted with nitrogen, used to burn reduced heating value fuel. Two $\mathrm{N}_{2}$ to $\mathrm{CH}_{4}$ ratios by volume are used: 2.25 (baseline) and 3.0. The fuel higher heating values are about 17,000 and $14,000 \mathrm{~kJ} / \mathrm{kg}$, respectively. The equivalence ratio range examined is $0.45 \Phi$ to $0.65 \Phi$. The flame zone is well aerated with a blue luminosity exhibited. The CRN consists of three chemical reactor elements placed in series: (1) adiabatic perfectly stirred reactor operating at incipient blowout (PSB), (2) adiabatic perfectly stirred reactor (PSR), and (3) nonadiabatic plug flow reactor operating at an assigned (measured) temperature (PFT). The volume of the PSB is computed for each case; this volume is adjusted by the code automatically. The volumes of the PSR and PFT are fixed and not changed. The PSB is used to ignite the fuel-air mixture and represent the flame front. The PSR is used to model the flame and the immediate post-flame, and the PFT is used to represent the burnout section. 


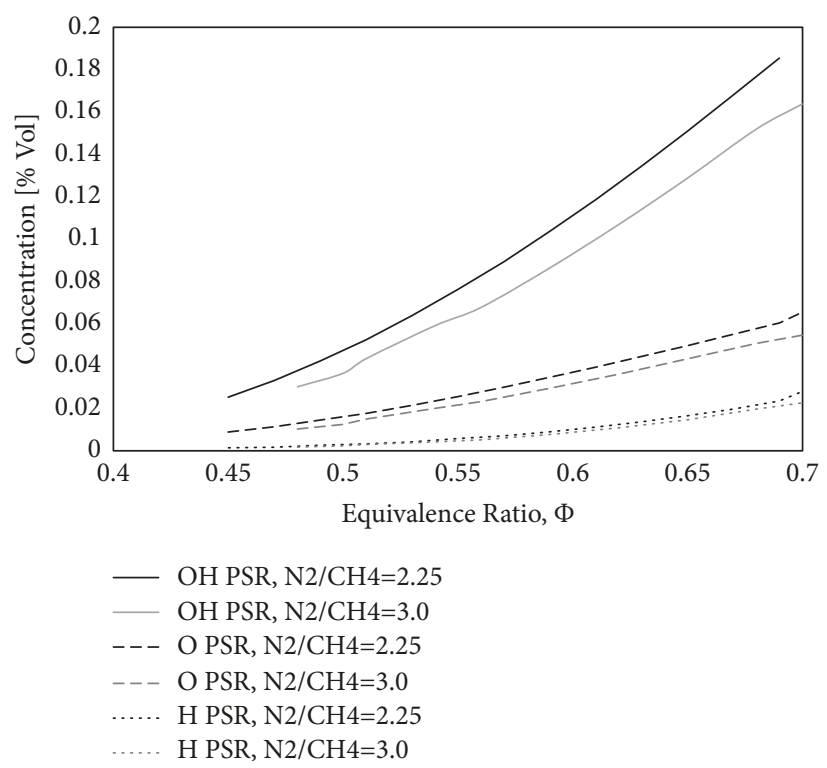

FIGURE 7: CRN-predicted concentrations of $\mathrm{OH}, \mathrm{O}$, and $\mathrm{H}$ in the PSR zone, over a lean regime until LBO. The nominal PSR residence time is $2 \mathrm{~ms}$.

Comparison with the Experimental Data. The phenomenological 3-element CRN is in good agreement with several experimental observations. The CRN shows a steep increase in the PSB volume at the experimental LBO conditions, indicating that the combustor is operating in the proximity of lean flame blowout (LBO). The CRN shows the near constant $\mathrm{CO}$ concentration in the flame zone as the equivalence ratio is varied. The $\mathrm{CRN}$ trends agree with the measured exhaust concentrations of $\mathrm{CO}$ and UHC over the range of the equivalence ratio. The model predictions can be improved by adjusting the mixing of the bypass to the PFT zone, introducing a more refined model reflecting the flow patterns, and the addition of the heat loss subroutine. CO oxidation in the probe needs to be further investigated. The probe can be modeled by the addition of a PFR element [65]. The probe calculations would add to the model runtime; these were not performed here as the focus of this work is demonstrate a proof-of-concept for real-time calculation of proximity to LBO which occurs upstream of the stack measurement location. However, the stack and probe modeling can be important for optimizing the emissions or the combustor efficiency.

Use of the CRN for Real-Time System Performance Analysis. The approach presented here can be used for the realtime monitoring of combustor performance, prediction of the emission trends, and estimation of difficult-to-measure system parameters, such as the proximity to blowout, combustion efficiency, and pollution emission rates. One of the most interesting findings is the potential use of the CRN as a predictive tool for combustion stability monitoring. Approaching LBO, the CRN predicts an approximately linear decrease of ground state $\mathrm{OH}$ concentration to a value of about $0.025 \%$. This threshold value may not be universal and needs to be determined for a specific reactor. However, the

trends leading to the LBO are clear and should be further investigated and validated experimentally. Other threshold values and ratios of rates and concentrations may be considered to show method robustness and applicability to practical combustion systems.

Generalization. A low computational cost model can be developed for a specific system and a range of operational parameters. CFD can assist in the construction of such a system similar to the ERN approach to account for flow structures in the reactor. However, the main objective of this work is to demonstrate a model that can describe the trends of the system over a range of fuels and operating conditions in real-time. This work demonstrates the use of CRN for monitoring the combustion of low heating value fuels, specifically the proximity to blowout based on $\mathrm{OH}$ radical trends. The measurements of free radical are difficult in most real-world applications. The model-based approaches can be used in a variety of combustion systems to monitor combustion trends with respect to system pollution formation, combustion efficiency, and proximity to a blowout.

\section{Nomenclature and Definitions}

AFT:

$\mathrm{CO}:$

$\mathrm{CO}_{2-c c}$ :

CRN:
Adiabatic flame temperature Carbon monoxide Carbon dioxide at complete combustion Chemical Reactor Network, an arrangement of chemical reactor elements that describes the combustor

Dilution Ratio: Ratio of $\mathrm{N}_{2}$ to $\mathrm{CH}_{4}$ by volume in the fuel mixture 
Element: A chemical reactor, such as a PSR or PFR

ERN: Equivalent reactor network

Fuel: Methane with nitrogen

$\Phi$ : $\quad$ Fuel to air equivalence ratio

LBO: Lean flame blowout

$\mathrm{OH}$ : Hydrogen peroxide

PFR: $\quad$ Plug Flow Reactor, a reactor consisting of a one-dimensional flow, along which chemical change, without diffusion, occurs. Typically used to model the burnout zone of a combustor

PSB: $\quad$ A PSR operating at an incipient blowout. The chemical kinetic code calculates the PSB volume: first, the minimum PSR volume is calculated, and then one percent is added to the minimum volume to ensure sustained combustion in the element. In the manuscript, the PSB volume is referred to as an incipient blowout volume. PSB is typically used to model the flame front

PSR: $\quad$ Perfectly Stirred Reactor, a zero-dimensional reactor of spatially uniform temperature and chemical composition, in which the chemical rate is slow (controlling) compared to the mixing rate. It is typically used to model the luminous, primary flame and high-intensity recirculation zones. PSRs (and PSBs) are self-igniting

Slpm: Standard liters per minute

UHC: Unburned hydrocarbons, the sum of hydrocarbon gases measured by an unheated hydrocarbon analyzer, expressed as equivalent methane

XTZ: Experimental three-zone combustor

Zone: A region of the combustor of a particular characteristic, such as the luminous flame front, the primary flame zone, or the secondary burnout zone. The terms "zone" and "element" are used interchangeably in the CRN.

\section{Data Availability}

The data used to support the findings of this study are included within the article.

\section{Conflicts of Interest}

The authors declare that they have no conflicts of interest.

\section{Authors' Contributions}

The manuscript is based on the MSME project of Mr. Pieter DePape, who is responsible for the design and fabrication of the experimental rig. Mr. Depape performed the laboratory experiments and the initial data analysis and provided the original draft of the manuscript. Prof. Igor Novosselov is the academic advisor for Mr. DePape, is responsible for the overall direction of the project, and provided day-to-day guidance in the experimental and modeling work.

\section{Acknowledgments}

This research was partially funded by the USDA SBIR grant number 2014-33610-22601 under a subcontract to the University of Washington.

\section{References}

[1] Y. Liu, X. Sun, V. Sethi, D. Nalianda, Y.-G. Li, and L. Wang, "Review of modern low emissions combustion technologies for aero gas turbine engines," Progress in Aerospace Sciences, vol. 94, pp. 12-45, 2017.

[2] R. Tacina, "Combustor technology for future aircraft," in Proceedings of the 26th Joint Propulsion Conference, 1990.

[3] J. P. Longwell and M. A. Weiss, "High Temperature Reaction Rates in Hydrocarbon Combustion," Industrial \& Engineering Chemistry, vol. 47, no. 8, pp. 1634-1643, 1955.

[4] G. C. Williams, H. C. Hottel, and A. C. Scurlock, "Flame stabilization and propagation in high velocity gas streams," in Proceedings of the 3rd Symposium on Combustion and Flame and Explosion Phenomena, pp. 21-40, Elsevier, USA, September 1948.

[5] S. Yamaguchi, N. Ohiwa, and T. Hasegawa, "Structure and blowoff mechanism of rod-stabilized premixed flame," Combustion and Flame, vol. 62, no. 1, pp. 31-41, 1985.

[6] S. Chaudhuri, S. Kostka, M. W. Renfro, and B. M. Cetegen, "Blowoff dynamics of bluff body stabilized turbulent premixed flames," Combustion and Flame, vol. 157, no. 4, pp. 790-802, 2010.

[7] M. Stöhr, I. Boxx, C. Carter, and W. Meier, "Dynamics of lean blowout of a swirl-stabilized flame in a gas turbine model combustor," Proceedings of the Combustion Institute, vol. 33, no. 2, pp. 2953-2960, 2011.

[8] J. P. Longwell, E. E. Frost, and M. A. Weiss, "Flame stability in bluff body recirculation zones," Industrial \& Engineering Chemistry, vol. 45, no. 8, pp. 1629-1633, 1953.

[9] Y. Guan and I. Novosselov, "Damkohler number analysis in lean blow-out of toroidal jet stirred reactor," Journal of Engineering for Gas Turbines and Power, vol. 140, no. 10, p. 104501, 2018.

[10] G. Ceglia, S. Discetti, A. Ianiro, D. Michaelis, T. Astarita, and G. Cardone, "Three-dimensional organization of the flow structure in a non-reactive model aero engine lean burn injection system," Experimental Thermal and Fluid Science, vol. 52, pp. 164-173, 2014.

[11] P. Malbois, E. Salaün, B. Rossow et al., "Quantitative measurements of fuel distribution and flame structure in a leanpremixed aero-engine injection system by kerosene/OH-PLIF measurements under high-pressure conditions," Proceedings of the Combustion Institute, 2018.

[12] P. Malbois, E. Salaun, F. Frindt et al., "Experimental investigation with optical diagnostics of a lean-premixed aeroengine injection system under relevant operating conditions," in Proceedings of the ASME Turbo Expo 2017: Turbomachinery Technical Conference and Exposition, American Society of Mechanical Engineers, Charlotte, NC, USA, 2017. 
[13] N. Kahraman, S. Tangöz, and S. O. Akansu, "Numerical analysis of a gas turbine combustor fueled by hydrogen in comparison with jet-A fuel," Fuel, vol. 217, pp. 66-77, 2018.

[14] A. Innocenti, A. Andreini, B. Facchini, and A. Peschiulli, "Numerical analysis of the dynamic flame response of a spray flame for aero-engine applications," International Journal of Spray and Combustion Dynamics, vol. 9, no. 4, pp. 310-329, 2017.

[15] J.-M. Lourier, M. Stöhr, B. Noll, S. Werner, and A. Fiolitakis, "Scale Adaptive Simulation of a thermoacoustic instability in a partially premixed lean swirl combustor," Combustion and Flame, vol. 183, pp. 343-357, 2017.

[16] S. Tachibana, K. Saito, T. Yamamoto, M. Makida, T. Kitano, and R. Kurose, "Experimental and numerical investigation of thermo-acoustic instability in a liquid-fuel aero-engine combustor at elevated pressure: Validity of large-eddy simulation of spray combustion," Combustion and Flame, vol. 162, no. 6, pp. 2621-2637, 2015.

[17] A. N. Lipatnikov, "Stratified turbulent flames: recent advances in understanding the influence of mixture inhomogeneities on premixed combustion and modeling challenges," Progress in Energy and Combustion Science, vol. 62, pp. 87-132, 2017.

[18] G. J. Sturgess et al., "Lean Blowout in a Research Combustor at Simulated Low Pressures," in Proceedings of the ASME 1991 International Gas Turbine and Aeroengine Congress and Exposition, Orlando, Florida, USA, 1991.

[19] D. R. Ballal, M. D. Vangsness, S. P. Heneghan, and G. J. Sturgess, "Studies of lean blowout in a research combustor," in AGARD, Fuels and Combustion Technology for Advanced Aircraft Engines, vol. 536, p. 9, 1993.

[20] D. R. Ballal et al., "Studies of Lean Blowout in a Research Combustor," in Proceedings of the AGARD Conference, vol. 536, 1993.

[21] S. Z. Vijlee, I. V. Novosselov, and J. C. Kramlich, "Effects of composition on the flame stabilization of alternative aviation fuels in a toroidal well stirred reactor," in Proceedings of the ASME Turbo Expo 2015: Turbine Technical Conference and Exposition, GT 2015, American Society of Mechanical Engineers, Canada, June 2015.

[22] M. Stohr et al., "Dynamics of lean blowout of a swirl-stabilized flame in a gas turbine model combustor," Proceedings of the Combustion Institute, vol. 33, pp. 2953-2960, 2011.

[23] R. W. Schefer, "Hydrogen enrichment for improved lean flame stability, International Journal of Hydrogen Energy, vol. 28, no. 10, pp. 1131-1141, 2003.

[24] A. Innocenti, A. Andreini, D. Bertini, B. Facchini, and M. Motta, "Turbulent flow-field effects in a hybrid CFD-CRN model for the prediction of NOx and $\mathrm{CO}$ emissions in aero-engine combustors," Fuel, vol. 215, pp. 853-864, 2018.

[25] B. Hu, Y. Huang, and J. Xu, "A hybrid semi-empirical model for lean blow-out limit predictions of aero-engine combustors," Journal of Engineering for Gas Turbines and Power, vol. 137, no. 3, p. 031502, 2015.

[26] A. Kaluri, P. Malte, and I. Novosselov, "Real-time prediction of lean blowout using chemical reactor network," Fuel, vol. 234, pp. 797-808, 2018.

[27] M. F. Karalus, K. B. Fackler, I. V. Novosselov, J. C. Kramlich, and P. C. Malte, "A skeletal mechanism for the reactive flow simulation of methane combustion," in Proceedings of the ASME Turbo Expo 2013: Turbine Technical Conference and Exposition (GT '13), San Antonio, Tex, USA, June 2013.

[28] D. G. Nicol, "The chemical reactor model combustion code," in NOx and CO Emissions Models for Gas-Fired, Lean Premixed
Combustion Turbine: Final Report, M. Mellor, Ed., Vanderbilt University, Nashville, Tenn, USA, 1996.

[29] I. V. Novosselov and P. C. Malte, "Development and application of an eight-step global mechanism for CFD and CRN simulations of lean-premixed combustors," Journal of Engineering for Gas Turbines and Power, vol. 130, no. 2, p. 021502, 2008.

[30] S. L. Bragg, Application of Reaction Rate Theory to Combustion Chamber Analysis, Aeronautical Research Council Pub, London, UK, 1953.

[31] J. Swithenbank, “Combustion Fundamentals," AFOSR 70-2110 TR, 1970.

[32] T. Rutar and P. C. Malte, " $\mathrm{No}_{x}$ formation in high-pressure jetstirred reactors with significance to lean-premixed combustion turbines," Journal of Engineering for Gas Turbines and Power, vol. 124, no. 4, pp. 776-783, 2002.

[33] A. Schlegel, P. Benz, T. Griffin, W. Weisenstein, and H. Bockhorn, "Catalytic stabilization of lean premixed combustion: Method for improving NOx emissions," Combustion and Flame, vol. 105, no. 3, pp. 332-340, 1996.

[34] A. S. Feitelberg, V. E. Tangirala, R. A. Elliott, R. E. Pavri, and R. B. Schiefer, "Reduced NOx diffusion flame combustors for industrial gas turbines," Journal of Engineering for Gas Turbines and Power, vol. 123, no. 4, pp. 757-765, 2001.

[35] K. B. Fackler et al., "NOx Behavior for Lean-Premixed Combustion of Alternative Gaseous Fuels," Journal of Engineering for Gas Turbines and Power, vol. 138, no. 4, p. 041504, 2016.

[36] G. Sturgess and D. T. Shouse, "A hybrid model for calculating lean blowouts in practical combustors," AIAA Paper, vol. 96, p. 3125, 1996.

[37] P. M. Rubins and D. T. Pratt, "Zone combustion model development and use: application to emissions control," American Society of Mechanical Engineers, pp. 91-25, 1991.

[38] A. Bhargava, M. Colket, W. Sowa, K. Casleton, and D. Maloney, "An experimental and modeling study of humid air premixed flames," Journal of Engineering for Gas Turbines and Power, vol. 122, no. 3, pp. 405-411, 2000.

[39] S. Zeppieri and M. Colket, "Fingerprint of hydrocarbon emissions from gas Turbine exhaust at low power," Combustion Science and Technology, vol. 186, no. 12, pp. 1991-2009, 2014.

[40] I. V. Novosselov, Eight-Step Global Kinetic Mechanism on Methane Oxidation with Nitric Oxide Formation for LeanPremixed Combustion Turbines, University of Washington, 2001.

[41] I. V. Novosselov, Chemical Reactor Networks for Combustion Systems Modeling [Ph.D. thesis], 2006.

[42] V. Fichet, M. Kanniche, P. Plion, and O. Gicquel, "A reactor network model for predicting NOx emissions in gas turbines," Fuel, vol. 89, no. 9, pp. 2202-2210, 2010.

[43] S. Lyra and R. S. Cant, "Analysis of high pressure premixed flames using Equivalent Reactor Networks for predicting NOx emissions," Fuel, vol. 107, pp. 261-268, 2013.

[44] R. J. Kee et al., "A Fortran computer code package for the evaluation of gas-phase multi-component transport properties," Technical Report SAND86-8246, Sandia National Laboratories, 1986.

[45] R. Kee et al., CHEMKIN-PRO, Reaction Design. Inc., San Diego, Calif, USA, 2008.

[46] R. J. Robertus, K. L. Nielsen, C. T. Crowe, and D. T. Pratt, "An Attempt to Reduce NOx Emissions from Pulverized Coal Furnaces," Environmental Science \& Technology, vol. 9, no. 9, pp. 859-862, 1975. 
[47] D. Benedetto et al., "NOx emission prediction from 3-D complete modelling to reactor network analysis," Combustion Science and Technology, vol. 153, no. 1, pp. 279-294, 2000.

[48] T. Faravelli et al., "A new procedure for predicting NOx emissions from furnaces," Computers \& Chemical Engineering, vol. 25, no. 4-6, pp. 613-618, 2001.

[49] M. Falcitelli, S. Pasini, N. Rossi, and L. Tognotti, "CFD+reactor network analysis: An integrated methodology for the modeling and optimisation of industrial systems for energy saving and pollution reduction," Applied Thermal Engineering, vol. 22, no. 8, pp. 971-979, 2002.

[50] S. Niksa and G.-S. Liu, "Incorporating detailed reaction mechanisms into simulations of coal-nitrogen conversion in p.f. flames," Fuel, vol. 81, no. 18, pp. 2371-2385, 2002.

[51] S. Niksa and G.-S. Liu, "Pulverized coal flame structures at elevated pressures. Part 2. Interpreting NOX production with detailed reaction mechanisms," Fuel, vol. 84, no. 12-13, pp. 15751585, 2005.

[52] S. Niksa et al., "Predicting NOX Emissions from Biomass Cofiring," in Proceedings of the 28th International Technical Conference on Coal Utilization \& Fuel Systems, Coal Technology Association, Clearwater, Fla, USA, March 2003.

[53] C. Di Blasi, "Modeling chemical and physical processes of wood and biomass pyrolysis," Progress in Energy and Combustion Science, vol. 34, no. 1, pp. 47-90, 2008.

[54] E. Ranzi, S. Pierucci, P. C. Aliprandi, and S. Stringa, "Comprehensive and detailed kinetic model of a traveling grate combustor of biomass," Energy \& Fuels, vol. 25, no. 9, pp. 41954205, 2011.

[55] D. T. Pratt and J. D. Wormeck, "CREK, Combustion Reaction Equilibrium and Kinetics in Laminar and Turbulent Flows," Report TEL-76-1, Department of Mechanical Engineering, Washington State University, Pullman, Wash, USA, 1976.

[56] D. T. Pratt and K. Radhakrishnan, "CREK1D: A computer code for transient, gas-phase combustion kinetics," NASA Technical Memorandum, 1984.

[57] K. Radhakrishnan and D. T. Pratt, "Fast Algorithm for Calculating Chemical Kinetics in Turbulent Reacting Flow," Combustion Science and Technology, pp. 155-176, 1988.

[58] D. T. Pratt, "Calculation of chemically reactive flows with complex chemistry," in Studies in Convection, B. E. Launder, Ed., vol. 2, Academic Press, 1997.

[59] M. F. Karalus, An Investigation of Lean Blowout of Gaseous Fuel Alternatives to Natural Gas, 2014.

[60] K. Radhakrishnan, "Fast Algorithm for Calculating Chemical Kinetics in Turbulent Reacting Flow," Combustion Science and Technology, vol. 58, no. 1-3, pp. 155-176, 1988.

[61] S. Bjornsson, Advanced Control Methodology for Biomass Combustion [M. S. Thesis], University of Washington, Seattle, Wash, USA, 2014.

[62] T. M. Muruganandam, S. Nair, D. Scarborough et al., "Active control of lean blowout for turbine engine combustors," Journal of Propulsion and Power, vol. 21, no. 5, pp. 807-814, 2005.

[63] Gaydon, The spectroscopy of flames, Wiley, New York, NY, USA, 1974.

[64] T. Kathrotia, U. Riedel, A. Seipel, K. Moshammer, and A. Brockhinke, "Experimental and numerical study of chemiluminescent species in low-pressure flames," Applied Physics B: Lasers and Optics, vol. 107, no. 3, pp. 571-584, 2012.
[65] J. C. Kramlich and P. C. Malte, "Modeling and Measurement of Sample Probe Effects on Pollutant Gases Drawn from Flame Zones," Combustion Science and Technology, vol. 18, no. 3-4, pp. 91-104, 1978. 


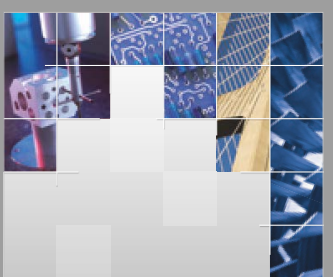

\section{Enfincering}
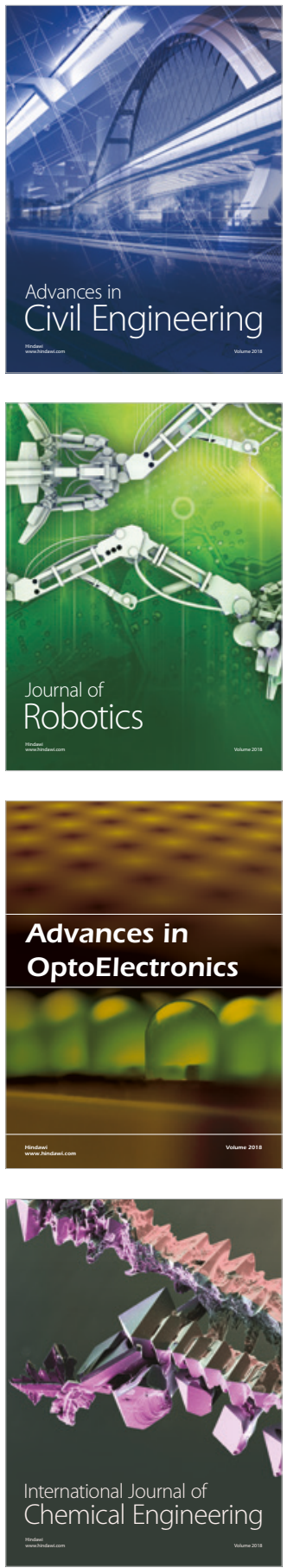

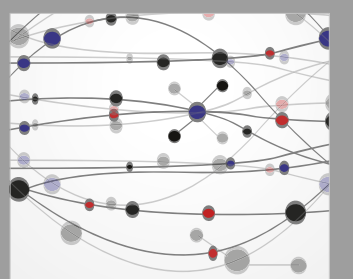

\section{Rotating \\ Machinery}

The Scientific World Journal

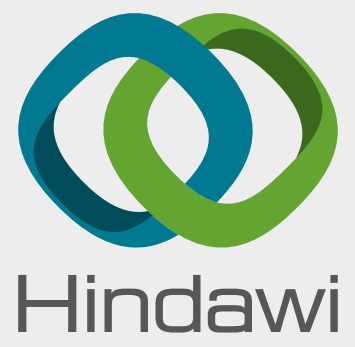

Submit your manuscripts at

www.hindawi.com
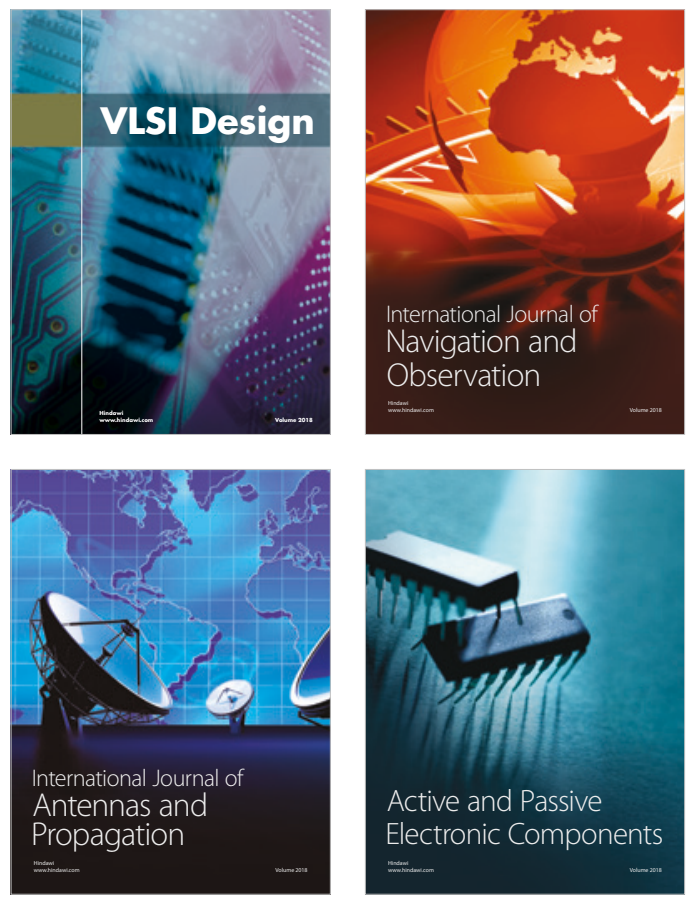
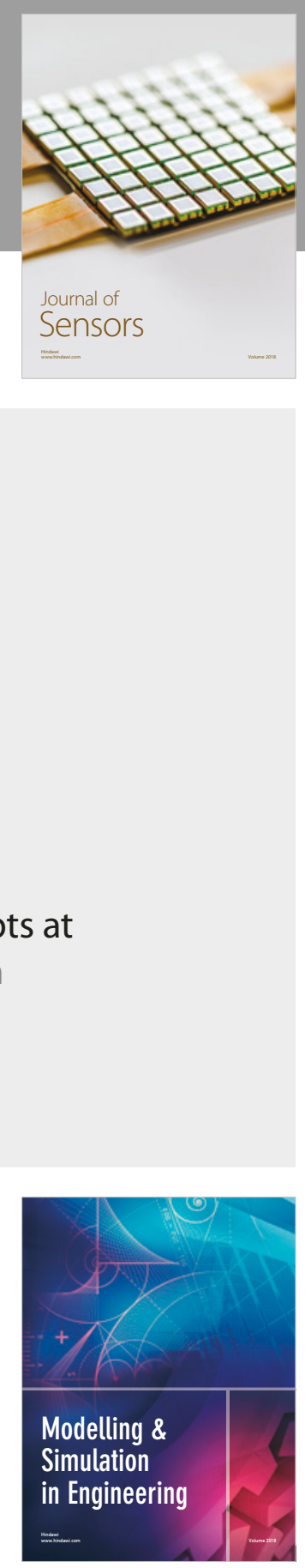

\section{Advances \\ Multimedia}
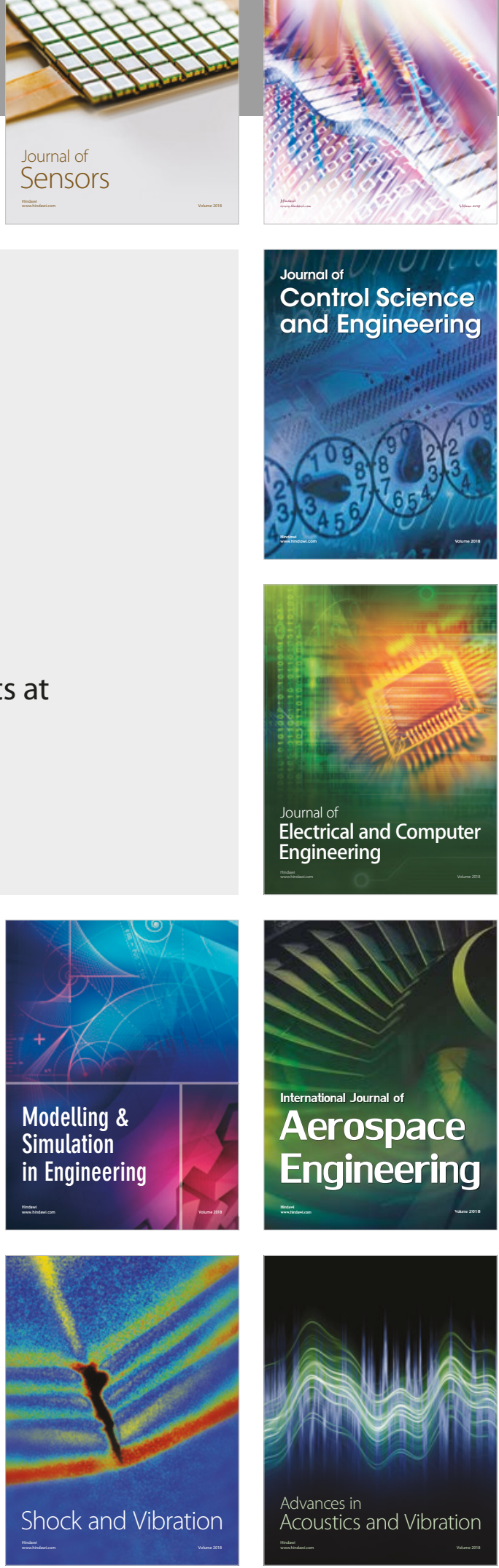